\title{
KAJIAN MAKNA PANIL 13, PADA RELIEF LALITAVISTARA \\ CANDI BOROBUDUR
}

\author{
Andi Farid Hidayanto \\ Staf Pengajar Jurusan Desain Politeknik Negeri Samarinda \\ e-mail: gandhyie@yahoo.com
}

\begin{abstract}
Abstrak
Borobudur temple in Indonesia as the largest temple is the ancestral filled with meaning stored in it. both in terms of shape, dimensions, levels, and reliefs. The reliefs depict an ongoing narrative between the panels with other woods panels forming the course of a story. To learn the hidden meaning in these panels can be used several methods. one of which is a method of iconography. with this method in order to obtain proper perspective to understand the background of an object being observed so that helps provide information on the history, politics, and life at a time. so as to know what the meaning is stored in one of the panels.

Keywords: iconography, Borobudur, panil $13^{\text {rd }}$
\end{abstract}

\begin{abstract}
Abstrak
Candi Borobudur sebagai candi terbesar di Indonesia merupakan peninggalan nenek moyang yang penuh dengan makna yang tersimpan di dalamnya. Baik dari sisi bentuk, dimensi, tingkatan maupun reliefnya. Relief-relief tersebut menggambarkan suatu cerita yang berkesinambungan antara panil satu dengan panil lainnya membentuk jalannya sebuah cerita. Untuk mempelajari makna yang tersembunyi pada panil tersebut dapat digunakan beberapa metode. Salah satunya adalah metode Ikonografi. Dengan metode ini agar dapat diperoleh sudut pandang yang tepat untuk memahami latar belakang suatu objek yang diamati sehingga membantu memberi keterangan mengenai sejarah, politik, serta kehidupan pada suatu masa. Sehingga dapat diketahui apa makna yang tersimpan dalam suatu panil tersebut.
\end{abstract}

Kata kunci: ikonografi, Borobudur, Panil 13

\section{Pendahuluan}

Candi Borobudur terletak di Desa Borobudur, Kecamatan Borobudur, Kabupaten Magelang, Propinsi Jawa Tengah. Siluet Borobudur adalah sebuah bangunan seperti stupa, sebagai situs untuk meditasi para biarawan Budhis. De Casparis menyarankan adanya kemungkinan bahwa bangunan Borobudur mungkin adalah juga candi (Claire Holt, 1967: 42). Sepuluh pelataran yang dimiliki Borobudur tersebut menggambarkan filsafat mazhab Mahayana. Yang menggambarkan sepuluh tingkatan Bodhisattva yang harus dilalui untuk mencapai kesempurnaan menjadi Budha. Borobudur pada hakikatnya merupakan tiruan dari alam semesta. Pembagian vertikal secara filosofis meliputi tingkat Kamadhatu, 


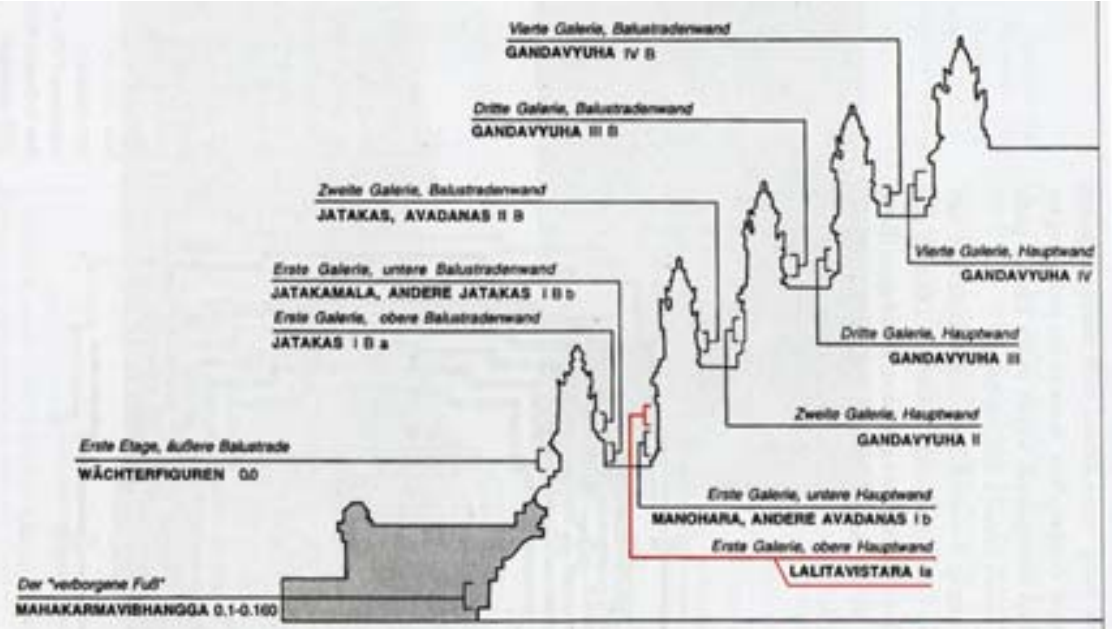

Gambar 1. Skema pembagian relief Borobudur dan lokasi relief Lalitavistara Sumber: www.borobudurforumdesain.htm

Rupadhatu, dan Arupadhatu. Pembagian vertikal secara teknis meliputi bagian bawah, tengah, dan atas (Soetarno, 2002: 85).

Candi Borobudur mempunyai 1.460 panil relief cerita yang tersusun dalam 11 deretan mengitari bangunan candi dan relief dekoratif berupa relief hias sejumlah 1.212 panil. Relief cerita pada tingkat Kamadhatu (kaki candi) mewakili dunia manusia menggambarkan perilaku manusia yang masih terikat oleh nafsu duniawi. Hal ini terlihat pada dinding kaki candi yang asli terpahatkan 160 panil relief Karmawibhangga yang menggambarkan hukum sebab akibat dari perilaku manusia. Tingkat Rupadhatu (badan candi) mewakili dunia antara, menggambarkan perilaku manusia yang sudah mulai meninggalkan keinginan duniawi, akan tetapi masih terikat oleh suatu pengertian dunia nyata. Pada tingkatan ini dipahatkan 1.300 panil yang terdiri dari relief Lalitavistara, Jataka, Avadana, dan Gandawyuha (Noerhadi, 1997: 361). Tingkat arupadhatu berupa tingkatan candi yang tidak mempunyai relief namun mempunyai stupa-stupa menggambarkan dunia tanpa bentuk. Akhir bangunan paling atas dihiasi dengan bangunan stupa tunggal sebagai puncak bangunan.

Relief Lalitavistara terdiri atas 120 panil. Panil 13 terdapat di tingkat pertama pada dinding atas relief Lalitavistara, sebelah dinding barat Candi Borobudur. Panil 13 ini merupakan panil terpendek dengan panjang $185 \mathrm{~cm}$.

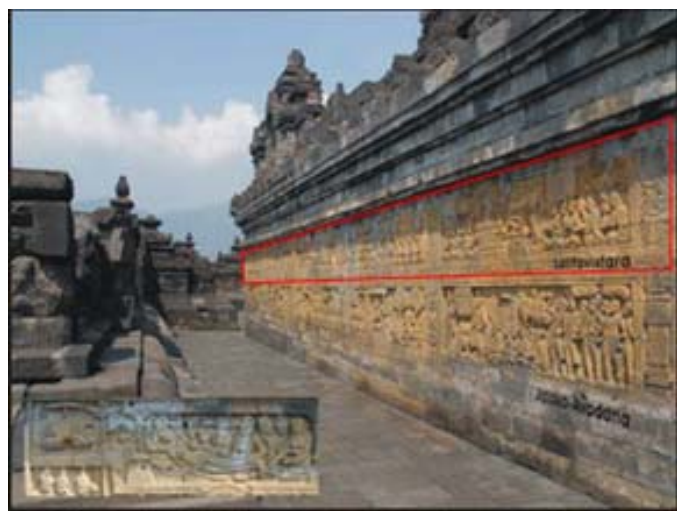

Gambar 2. Posisi panil 13

Sumber. www.borobudurforumdesain.htm 


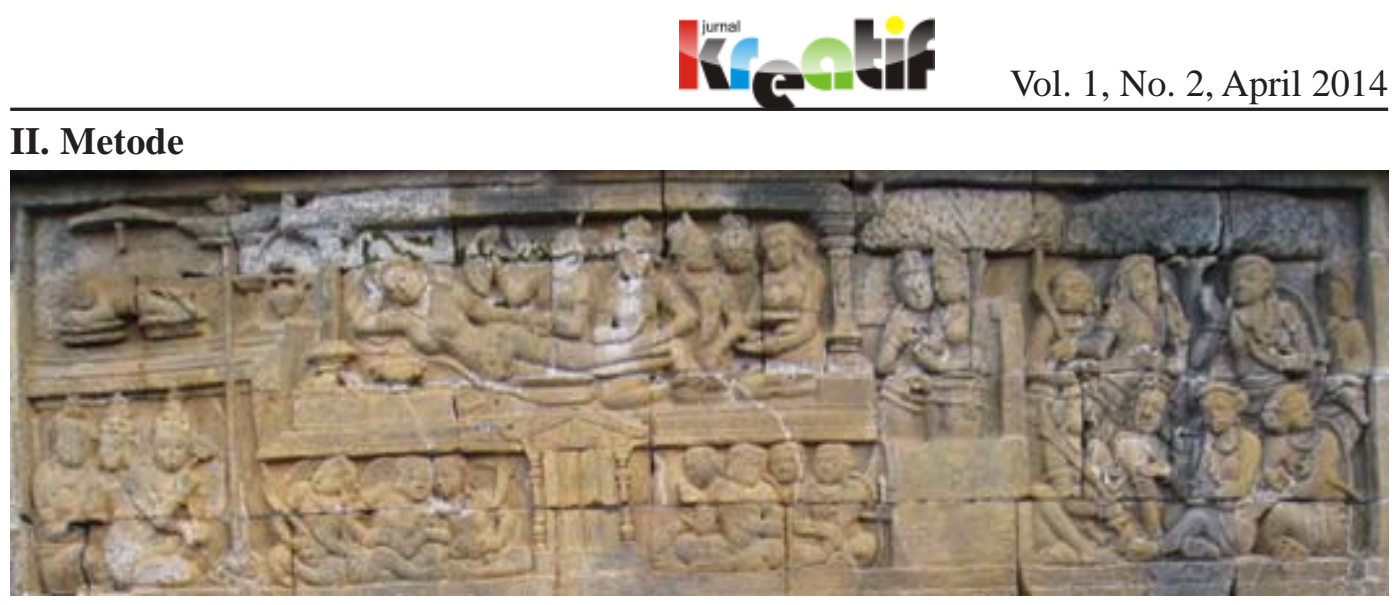

Gambar 3. Panil 13, pada relief di dinding barat Candi Borobudur

Sumber: www.kaskus.co.id/lalitavistara-page1.htm

Candi Borobudur merupakan karya seni klasik. Dalam membaca karya seni klasik, terdapat tiga unsur, yaitu seniman, karya dan pembaca/penonton (Dick Hatoko, 1984: 40). Seniman adalah orang yang mengerjakan karya tersebut. Hasil tiap seniman berbeda-beda, sesuai jaman dan kondisinya. Karya adalah artefak yang merupakan bukti karya seniman yang berwujud benda. Adapun pembaca adalah orang yang melihat hasil karya tersebut, tanpa ada batasan waktu selama karya tersebut masih ada. Candi Borobudur dibuat oleh seniman dari masa Mataram kuno, tentunya konsep berkarya pada masa itu berbeda dengan masa sekarang. Karya seni lahir dan hadir dalam hubungan yang kontekstual dengan ruang dan waktu tempat karya tersebut dilahirkan. Kelahiran sebuah karya seni karena dimotivasi berbagai persoalan dan kejadian dalam masyarakat pada waktu itu. Proses mengelola realitas ini ke dalam karya seni ini disebut pencitraan (AIS, 2008: 1-2).

Untuk bisa membaca karya tersebut perlu dipelajari makna yang tersembunyi. Salah satu metode membaca makna tersebut dengan metode Erwin Panofsky tentang Ikonografi. Erwin Panofsky (1955) menjelaskan ikonografi merupakan kajian yang memperhatikan konfigurasi dari gambar pada suatu karya untuk mengetahui makna yang tersembunyi. Selanjutnya Panofsky memberi tahapan dalam menganalisis, yaitu tahap pre-ikonografi, ikonografi dan ikonologi:

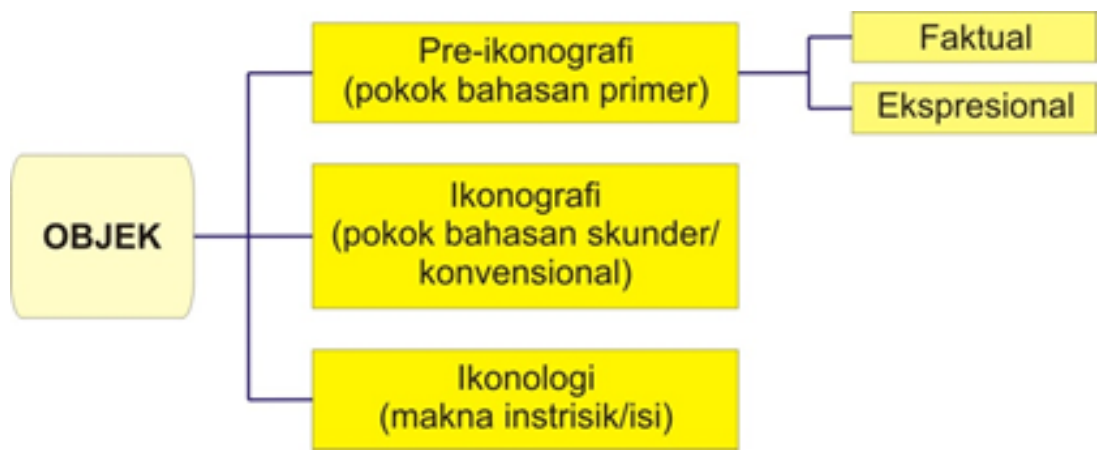

Gambar 4. Penjabaran makna objek menurut Erwin Panofsky 
Andi Farid Hidayanto, Kajian Makna Panil 13, Pada Relief Lalitavistara Candi Borobudur

Menurut Ratnaesih Maulana (1992) dalam Ikonografi Hindu dan Budha, kata ikon dipakai secara lebih khusus. Kata itu tidak ditujukan kepada materi gambar, tetapi pada tokoh yang digambarkan dan kemiripan tokoh yang dinyatakan dalam gambar dengan tujuan untuk mengadakan hubungan dengan tokoh atau dewa tersebut. Tujuan seniman mencipta tokoh tersebut adalah untuk mempertinggi martabat dan bukan untuk kepuasan dirinya. Seniman yang memahat karya tersebut berprinsip bahwa jiwanya yang murni akan mendapat sejahtera di sorga.

\section{Pembahasan}

\section{Tahap Pre-ikonografi}

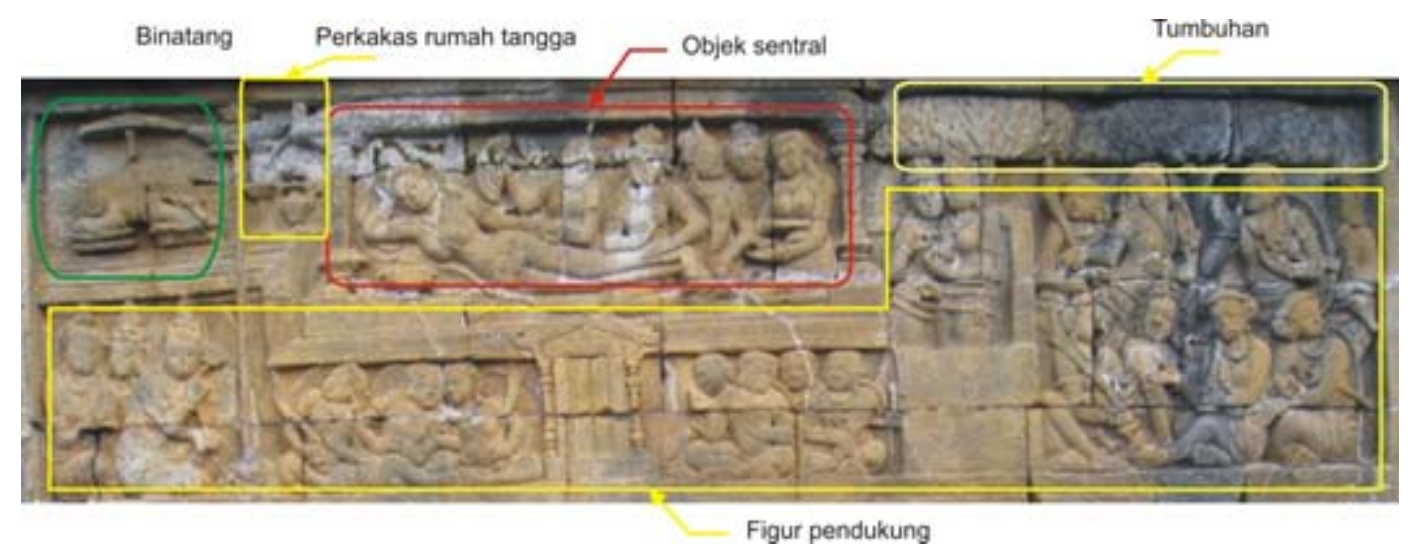

Gambar 5. Makna tahap pre-ikonografi

Dengan posisi panel horizontal, dalam relief ini tampak beberapa figur manusia, pohon, bangunan, perkakas rumah tangga dan binatang. Sosok sentral pada panel ini adalah figur wanita sedang tidur di atas batu datar ditemani beberapa wanita.

Di sisi kiri atas ada figur gajah. Di sudut kiri bawah ada beberapa figur orang duduk. Di tengah bawah duduk sederetan figur orang dipisah oleh bangunan di tengahtengahnya. Di sisi kanan ada beberapa figur orang di bawah pohon. Figur pohon juga berfungsi sebagai pembatas bidang.
Relief di Candi Borobudur tersebut didesain dengan mengikuti aturan-aturan yang berasal dari arsitektur India (gaya Gandhara), dengan mengalami modifikasimodifikasi. Menurut Prasasti Klurak (784 M) pembuatan candi ini dibantu oleh seorang guru dari Ghandadwipa (Bengalore) bernama Kumaragacya yang sangat dihormati, dan seorang pangeran dari Kashmir bernama Visvawarman sebagai penasihat yang ahli dalam ajaran Buddha Tantra Vajrayana. Pada adegan yang berhubungan dengan kehidupan di bumi seperti panil 13, adegan tersebut memuat banyak informasi tentang arsitektur, peralatan rumah tangga, pakaian serta perhiasan, senjata, instrument musik serta gerak tari, tingkah laku, fungsi serta sikap

Figur pendukung

para budak dan abdi, tipe-tipe manusia, binatang dan tumbuh-tumbuhan (Claire Holt, 2000: 40). Ciri-ciri gaya Gandhara pada panil 13 itu adalah:

- Bentuk relief tinggi. Awalnya terdapat dalam pahatan-pahatan seni relief Gandhara yang membuat figur tokoh-tokoh menjadi lebih menonjol dari bidang pahatan.

- Gaya naturalis. Salah satu ciri yang terdapat dalam pemahatan relief masa Klasik Tua. Gaya. Wajah dalam relief Candi Borobudur 
Vol. 1, No. 2, April 2014

digambarkan menghadap ke Bodhisattva dari surgawi Tusita masuk ke pengamat. dalam rahim Ratu Maya dalam bentuk gajah putih. Masuknya Bodhisattva ke rahim Ratu

- Adanya penggambaran lipatan kain (draperi). Relief gaya seni Gandhara sangat memperhatikan penggambaran lipatan kain, terutama pada bagian busana yang dikenakan oleh para tokoh. Lipatan kain itu digambarkan sangat halus dan naturalis, sehingga jatuhnya kain dan lipatan kain hampir seperti kenyataan sebenarnya.

Maya disaat Ratu sedang tidur.

Sri Mahamaya, permaisuri Raja Suddhodana dari kerajaan Kapilavatthu sedang menikmati kebahagiaan istana. Saat Permaisuri sedang menjalankan Delapan Sila dan berbaring di atas dipan yang indah, pada jaga terakhir di malam purnama itu, Siri Mahamaya jatuh tertidur dan bermimpi, yang

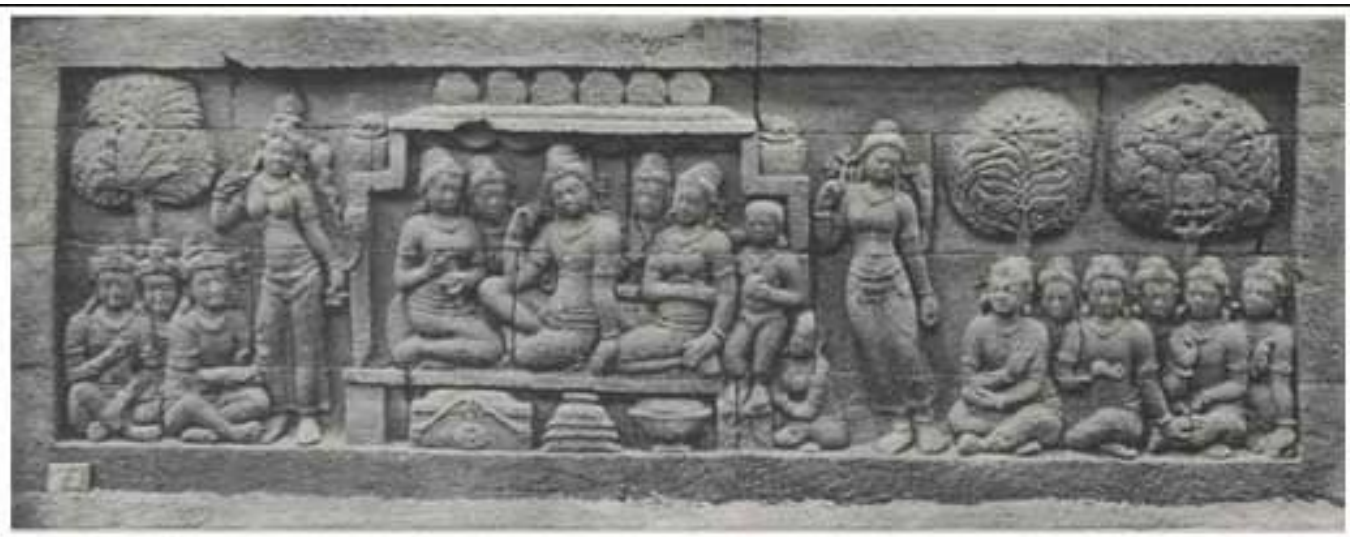

Gambar 6. Contoh ciri gandhara dalam salah satu relief karmavibhangga Candi Borobudur yang masih dalam kondisi baik, a). relief tinggi/timbul, b). digambarkan naturalis, c). adanya kain dan lipatan kain yang digambarkan seperti sebenarnya, walaupun tidak terlalu nyata.

Sumber: www.borobudurforumdesain.htm

Menurut Van der Hoop dalam tulisan Siti Rohyani (2004), hiasan dalam relief candi dibedakan atas motif geometris dan motif naturalistik. Motif geometris meliputi motif kotak-kotak, pilin, segi tiga (tumpal), swastika, kawung, jlamprang, pinggir awan dan lain sebagainya Motif naturalistik meliputi bentuk manusia, hewan dan tumbuhan.

\section{Tahap Ikonografi}

Panil 13 ini menceritakan Bodhisattva reinkarnasi ke generasi berikutnya. Reinkarnasi dengan turunnya merupakan pertanda masuknya Boddhisattva kedalam rahimnya.

Pada saat Ratu Maya sedang bermimpi, Boddhisattva Dewa Setaketu sedang berkeliling di Taman Nandavana di Surga Tusita, menikmati pemandangan dan suara yang indah. Pada saat itulah Beliau meninggal dunia dari Alam Tusita dengan penuh kesadaran. Pada saat itu juga Boddhisatta masuk ke rahim yang mirip teratai milik Permaisuri Ratu Mahamaya, dengan kesadaran agung. Peristiwa ini terjadi pada hari Kamis pagi pada hari purnama di bulan Asalha tahun 67 Maha Era, 
Andi Farid Hidayanto, Kajian Makna Panil 13, Pada Relief Lalitavistara Candi Borobudur

penanggalan yang ditetapkan oleh Raja Anjana, kakek Boddhisattva. Peristiwa ini ditandai dengan peristiwa bulan dan bintang Uttarasalha berada dalam posisi segaris. surgawi dan meriasnya dengan bunga-bunga surgawi. Figur Dayang di sisi istana lainnya digambarkan dengan dua figur dayang di bawah

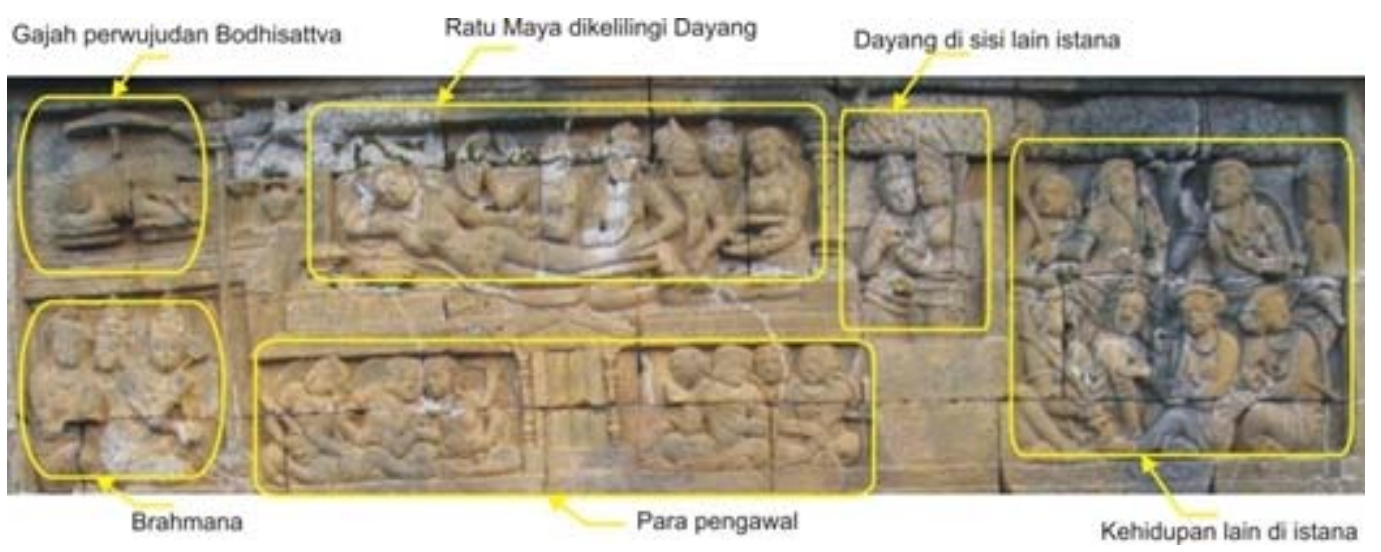

Gambar 7. Makna tahap ikonografi

Dari analisa ikonografi dari panil 13 tersebut ada beberapa makna, yaitu:

1. Dilihat dari pesan artifaktual pada panel ini, terdapat figur utama yang apabila dilihat ciri-ciri fisik dan asesories pakaian yang dipakainya merupakan bentuk figur Ratu Maya. Ekspresi Ratu Maya menggambarkan kebahagiaan karena sedang mengandung dalam posisi sedang tidur dan bermimpi.

2. Di bawah dipan ada beberapa figur digambarkan sebagai pasukan pengawal bersenjata lengkap. Dipan berukuran enam puluh yojana tempat Ratu Maya dibaringkan. Dipan tersebut digambar mengikuti bentuk Ratu Maya. Disekitar dipan ada seperangkat perkakas rumah tangga.

3. Figur para Dayang disekeliling Ratu Maya.

Dayang-dayang tersebut sedang memandikannya, memakaikan pakaian surgawi serta mendandaninya dengan kosmetik pohon. Batas antar ruang digambar dengan tiang di kiri kanannya.

4. Figur seekor gajah di sudut kiri atas.

Figur seekor gajah putih bersih dengan enam gading duduk di atas teratai di bawah payung menggambarkan figur Bodhisattva, sedang berjalan-jalan kemudian mengelilingi ratu ke arah kanan dan kemudian masuk ke rahimnya dari sebelah kanan.

5. Di sisi kanan ada sederetan figur orang yang menggambarkan sisi lain kehidupan di istana.

Dari analisa visual terhadap gambar-gambar pada panil ini dapat disimpulkan ciri-ciri visual sebagai berikut:

- Figur-figur yang ada saling mendukung jalannya cerita.

- Figur yang ada digambarkan dalam bentuk simbolis. 
Vol. 1, No. 2, April 2014

- Penggambaran figur dalam bentuk full postur, tidak terpotong oleh garis batu.

\section{Tahap Ikonologi}

Pada tahapan ini makna yang paling hakiki dan mendasar dari isi sebuah panil dipahami. Pemahaman mengenai makna intrinsik yang terdapat dalam sebuah objek diperoleh dengan mengungkapkan prinsipprinsip dasar yang kemudian dapat menunjukan perilaku sikap dasar dari sebuah bangsa, kurun waktu, strata sosial, ajakan religius atau filosofis tertentu.

1. Relief pada Candi Borobudur menceritakan kehidupan Buddha Gautama Shakyamuni. Panil yang akan dibuat dipilih dengan pertimbangan yang hati hati, agar panil tersebut, terjalin dengan panil berikutnya maupun sebelumnya.

2. Dalam panil 13 menceritakan adegan Dewi Maya sedang bermimpi seekor gajah putih bergading 6 memasuki tubuhnya, sebagai perlambang reinkarnasi Bodhisattva ke dalam anaknya.

3. Setiap panil memiliki tokoh utama yang diperkirakan hanya boleh dikerjakan oleh ahlinya, sementara figur-figur dan bagian lainnya yang kurang penting boleh dikerjakan oleh seniman biasa.

4. Putri Maya dilukiskan dengan ukuran yang lebih besar dan diletakkan di tengah bidang. Dengan demikian mata yang memandang panil tersebut segera menangkap tokoh utamanya. Ini memberi penekanan bahwa ceriteranya mengenai Dewi Maya calon ibu sang Budha. Kastanya yang tinggi dilukiskan dengan figur tubuhnya yang sempurna, sambil berbaringpun menampilkan keseimbangan. Bentuk hidungnya yang tinggi, bibir yang tidak terlalu tipis, buah dada yang berisi, guratan guratan garis pada leher dan bawah payudara adalah ikon-ikon yang menunjukkan keningratannya. Liuk lekuk pinggang yang menawan, dan ekpresi wajah yang menggambarkan beliau sedang bermimpi.

5. Bentuk mimpi digambarkan pada sudut kiri atas. Gajah bergading 6 turun dari surga Tusita dengan mengendarai bunga teratai adalah perwujudan Bodhisattva. Gambar binatang (gajah) merupakan perwujudan dari mahkluk kayangan yang sedang bermeditasi serta menggambarkan adegan-adegan kehidupan sang Budha.

6. Kamar permaisuri raja Sudhodana dilengkapi dengan alas tidur yang mengikuti lekuk badannya. Sebuah kendi (kumbha) terletak dekat kepalanya. Lima orang dayang melayaninya dengan mengibaskan kipas padanya secara lembut, memijit pergelangan tangannya, mengurut kaki dan jempol kakinya. Salah seorang dayang membuatnya nyaman dengan asap dupa beraroma wewangian yang diarahkan kepadanya.

7. Di sudut kiri bawah tampak beberapa brahmana yang menjaganya.

8. Dibagian tengah sebelah bawah duduk sederetan prajurit yang menjaga keamanan di depan istana (dengan lambang pintu gerbang yang tertutup) lengkap dengan senjatanya.

9. Dua orang dayang menggambarkan bagian istana yang lain. 
Andi Farid Hidayanto, Kajian Makna Panil 13, Pada Relief Lalitavistara Candi Borobudur

10. Sekelompok orang di sisi kanan menggambarkan penghuni istana lainnya.

11. Pohon besar menjadi pembatas bidang. Pohon selain sebagai pembatas antar jarak, juga sebagai komponen adegan. Dalam masyarakat agraris seperti Indonesia, unsur pohon diperlakukan secara khusus karena berhubungan dengan kehidupan manusia (Siti Rohani, 2004: 16).

Komposisi bidang menunjukkan perspektif pandangan mata burung. Penonton dituntun memandang dari atas ke bawah menembus dan melihat keseluruhan kejadian di dalam istana Ratu Maya. Wajah wajah pada tokoh utama tak pernah terpotong oleh garis potongan batu. Ini menandakan pemahatan diawali dengan membuat sketsa yang langsung pada permukaan batu, dan dikerjakan langsung disitu. Dalam pemahatan relief wajah tokoh-tokoh dibuat menghadap ke pengamat. Komposisi panil tersebut memiliki keleluasan dan kejelian sekaligus menunjukkan kepakaran seniman Shailendra yang mungkin dibantu oleh seniman Sanjaya sebagai bentuk partisipasi pada masa tersebut.
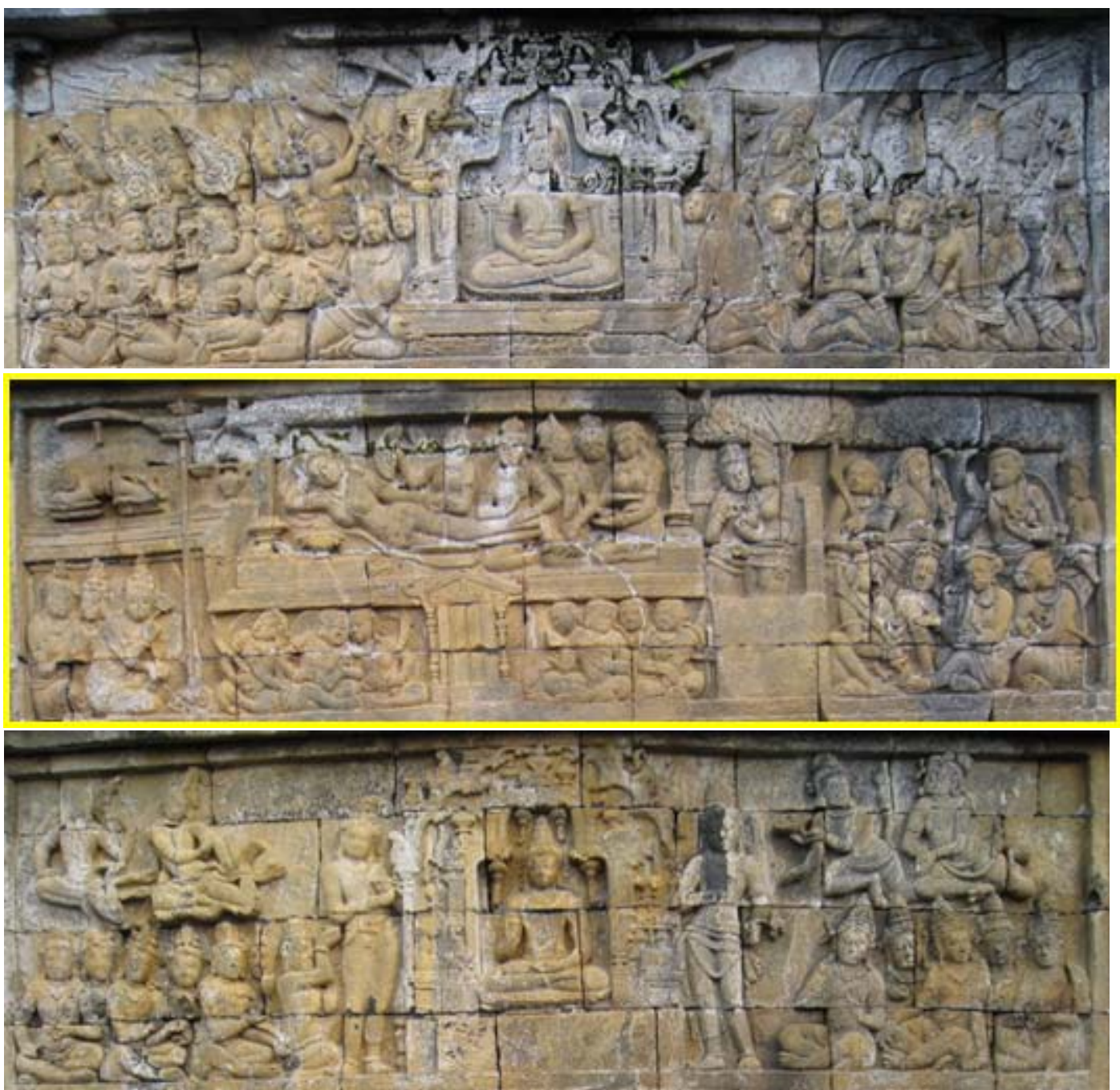

Gambar 8. Posisi panil 13 (tengah), terhadap panil 12 sebelumnya (atas) dan panil 14 (bawah) sesudahnya dalam membangun rangkaian cerita. 
Vol. 1, No. 2, April 2014

Panil 12: menceritakan Bodhisattva turun ke dunia. Dalam gambar Bodhisattva menempatkan dirinya di singasana yang berasal dari kebajikannya, selanjutnya beliau meninggalkan surga Tusita dikelilingi oleh seratus milyar koti bodhisattva, dewa, naga, dan yaksa.

Panil 13: Bodhisattva memasuki rahim Ratu Maya.

Panil 14: Bodhisattva di dalam rahim Ratu Maya. Setelah beliau memasuki rahim ibu-Nya, sebuah paviliun permata (Ratnavyuha) muncul untuk menaungi Bodhisattva, yang dalam kelahiran terakhirnya tidak mempunyai bentuk alami fetus. Di dalam paviliun beliau duduk bersila, lengkap dengan seluruh organ dan tanda-tanda. Diiringi oleh kumpulan makhluk surgawi dan membawa tetesan sari (teratai), Brahma mendekati istana permata Bodhisattva untuk memandangnya, mengaguminya dan melayaninya, dan untuk mendengar Dharma.

Untuk mengidentifikasi tokoh dalam relief menurut Siti Rohyani (2004) digunakan identifikasi berdasarkan sikap, busana dan asesori yang dikenakan para tokohnya. Busana dan asesoris tersebut berkaitan dengan kondisi sosial tokoh. Hiasan yang dikenakan ratu akan berbeda dengan yang dikenakan rakyat kebanyakan atau pendeta. Raja atau permaisuri biasanya digambarkan dalam bangunan yang indah, duduk dalam asana yang ditinggikan, atau digambarkan berada di alam terbuka, berdiri dekat sebuah bangunan. Raja dan Kerabat istana digambarkan dengan mengenakan hiasan badan yang lengkap berupa mahkota dan rambut ditata berupa pilinan yang disusun tinggi dan dihias batu permata.
Tokoh utama dalam panil tersebut, yaitu Ratu Maya digambarkan mengenakan upawita berupa untaian mutiara, antinganting panjang, kalung lebar dengan hiasan permata, kedua lengan memakai kelat bahu dengan hiasan simbar di bagian tengahnya. Gelang dikenakan pada tangan dan kaki berupa gelang untaian mutiara. Mengenakan kain dari bagian pinggang sampai sebatas mata kaki. Pada pinggang atau pinggul mengenakan ikat pinggang dengan hiasan bunga.

Hiasan badan yang dikenakan prajurit, dayang atau anggota kerajaan lain tidak selengkap hiasan yang dikenakan para kerabat kerajaan atau raja. Figur ini digambarkan duduk dalam sebuah bangunan, atau berdiri dekat bangunan. Hiasan yang digunakan biasanya rambut disisir halus dengan sanggul yang ditutup mahkota kecil atau mengenakan sanggul yang dihias bunga. Kadang-kadang hiasan rambut berupa pintalan rambut yang tidak terlalu tinggi dengan hiasan permata. Gelang yang dikenakan pada pergelangan tangan dan kaki berhias mutiara. Kelat bahu dengan hiasan simbar, pinggang mengenakan upawita dari tali polos. Kain yang dikenakan dari pinggang sampai mata kaki dan hiasan pinggang atau pinggul dari tali atau selendang dikenakan sebagai penguat dan hiasan. Orang kaya biasanya digambarkan dengan adanya kotak, koper,dan guci-guci perhiasan.

Orang kebanyakan atau rakyat jelata, petani, pengemis, nelayan mengenakan busana dan hiasan sederhana. Pada umumnya orang kebanyakan duduk atau berdiri di alam terbuka, di hutan, di bawah singgasana. Penggambaran tokoh laki-laki dengan rambut disisir ke balakang kadang-kadang diberi hiasan bunga, atau rambut dibiarkan terurai. Kaum wanita digambarkan dengan rambut tersusun dalam sanggul kecil tanpa hiasan. Pada telinga mengenakan anting-anting atau subang 
sederhana, kadang-kadang mengenakan gelang polos. Kaum laki-laki mengenakan kain yang diangkat pendek sehingga membentuk celana pendek atau cawat, sedangkan kaum wanita mengenakan kain sebatas lutut.

Golongan agamawan ada tiga, yaitu bhiksu, brahmana dan pertapa. Bhiksu digambarkan dengan kepala gundul, umumnya mengenakan jubah yang terbuka pada bagian pundak sebelah kanan, dan tanpa mengenakan asesoris. Kaum brahmana digambarkan dengan mengenakan tutup kepala atau sorban, hiasan telinga, gelang tangan, klat bahu, memakai kumis dan jenggot. Pertapa digambarkan digelung atau dikuncil, memakai gelang kaki, mengenakan anting, dan upawita. Kadang-kadang digambarkan berkumis dan berjenggot, serta membawa tasbih.

Tubuh dari tokoh kelas atas digambarkan dengan posisi tegap, sedangkan tubuh dari tokoh kelas bawah digambarkan dengan muka tertunduk. Arah gerak ditandai dengan posisi kaki dan kepala. Arah ini juga merupakan panduan dalam membaca ukiran, baik itu searah jarum jam (pradakshina) atau berlawanan dengan jarum jam (prasawya). Sebagian besar dari ukiran naratif menggambarkan alam dan elemenelemennya. Sebuah pohon bisa saja digambarkan terpisah dalam satu adegan yang terpisah dengan yang lainnya. Sebuah pohon atau pepohonan bisa jadi mencirikan pertapaan di hutan atau susana dalam keraton. Tingginya frekuensi kemunculan pohon tampaknya memiliki koneksi dengan penggambaran bangunan aristokrat.

Sebuah pemandangan yang lengkap direpresentasikan oleh bukit-bukit, pengunungan, ladang, fasilitas perairan, dan jalan. Pemandangan ini biasanya diukir dalam sudut pandang burung. Penggambaran dari pemandangan memiliki bermacam fungsi, untuk mencirikan lingkungan tertentu seperti pedesaan atau kraton, dapat 64 juga menyimbolkan sifat jahat dari alam, atau lingkungan tertentu di Jawa. Pemandangan itu juga merujuk kepada kekuatan raja dalam menjaga susunan kosmos dengan cara membentuk alam. Seperti pada karya literatur Jawa Kuno umumnya, pemandangan merupakan medium untuk menyampaikan keindahan dan sebagai bentuk kontribusi terhadap lango. Arsitektur pada gambaran candi dapat berupa istana, pertapaan, komplek candi, dan pemandian.

\section{KESIMPULAN}

Untuk mengetahui makna dan pola visual yang terdapat pada relief candi, maka pendekatan yang digunakan adalah pendekatan ikonografis dan ikonologis. Pendekatan yang digunakan untuk menganalisis relief candi melalui tiga tahapan seperti analisis makna secara ikonografi dan ikonologi oleh Erwin Panofsky dimana ketiga tahapan itu berlangsung berurutan. Erwin Panofsky menjelaskan dalam ikonografi merupakan kajian yang memperhatikan konfigurasi dari gambar pada suatu karya untuk mengetahui makna yang tersembunyi. Selanjutnya Panofsky memberi tahapan dalam menganalisis, yaitu tahap pre-ikonografi, ikonografi, dan ikonologi.

Faktor masa penciptaan menjadi penting untuk dibicarakan karena latar belakang, kondisi sosial, dan aspek psikologis berpengaruh pada pengambilan keputusan dalam menampilkan suatu gambar visual pada masa itu. Namun dalam hal ini, aspek yang diutamakan adalah aspek formal yang membahas aspek kualitas visual yang dikaji secara lebih mendalam. Sehingga dari analisis ikonografi dan ikonologi diharapkan akan menghasilkan sebuah hasil yang komprehensif untuk relief candi dengan mengkaitkan antara pola visual dan makna yang terdapat didalam karya tersebut. 
Vol. 1, No. 2, April 2014

Relief pada candi merupakan media untuk menyampaikan pesan. Pesan yang ingin disampaikan dikemas dalam rangkaian cerita yang menarik, sarat nilai keagamaan, dikemas dalam kehidupan sehari-hari agar mudah dipahami oleh masyarakat waktu itu (Siti Rohyani, 2004: 14). Dalam menyampaikan pesan, seniman memahat adegan tersebut dengan sangat komunikatif. Masyarakat dapat menangkap pesan yang disampaikan seniman karena mengungkapkan kehidupan sehari-hari. Dalam kesehariannya, masyarakat dapat menyaksikan atau melakukan seperti adegan-adegan dalam relief itu.

Relief dalam Candi Borobudur digambarkan dalam naturalistik. Karena seniman juga melukiskan perasaannya dalam karya itu. Seniman tidak hanya menggambarkan apa yang dilihatnya, melainkan apa yang diketahuinya dan dituangkan dalam karya tersebut (Dick Hartoko, 1984: 28).

Relief Candi Borobudur dinamis dalam komposisi, dramatik dalam mengungkapkan perasaan. Naturalisme diidealisasikan dari seni India. Alam-pohonair mengalami stilisai dekoratif. Adegan dalam relief Candi Borobudur merupakan penampilan untuk merenung, dengan kegembiraan sorgawi. Pengelompokan, tingkah laku dan wajah yang intens dari para pelaku, semuanya dalam aksi yang ekspresif. Para abdi, parjurit, dewa, maupun dayang bukanlah sekedar rombongan yang berlebihan. Mereka tampak mereaksi dan memberikan komentar atas peristiwaperistiwa yang terpampang dalam panil. Keikutsertaan mereka melibatkan mereka dengan akrab kepada Ratu Maya yang berhias dengan indah sekali. Mereka menambah keramaian. Figur mereka kadang tersembunyi pada daun-daunan. Tidak ada ketegangan atau kualitas dinamis yang kuat pada perwujudan figur-figur tersebut. Adegan-adegan tersebut adalah penampilan- penampilan gerak yang tanpa nafsu sama sekali, serta tanpa kesan dramatik. Ini semacam pelepasan yang menembus kematian serta kejernihan dari bentukbentuk yang indah. Roh yang lebih duniawi tampil pada figur-figur rakyat jelata, dayang, prajurit (Claire Holt, 2002: 50 - 64).

Relief dalam candi sebagai seni klasik di Indonesia tidak pernah luput dari simbol-simbol yang sangat dalam maknanya. Simbolisme-simbolisme tersebut menggambarkan alam pikiran masyarakat yang memilikinya pada saat tersebut. Susanne K. Langer menjelaskan bahwa simbol-simbol pada relief tersebut disebut the symbol in art yang harus dibedakan dengan the art symbol yang kemudian istilah ini diubahnya menjadi expressive form karena banyak menimbulkan salah paham. Dalam relief Candi Borobudur menjelaskan pemanfaatan seni dalam agama (religi) untuk menunjang kebesaran (keagungan) agama Budha. Relief Candi Borobudur seperti kitab suci terbuka dan semuanya siap dipelajari, tingkat-tingkat untuk mencapai ke Budhaan (Soedarso, 2006: 37-42). 
Andi Farid Hidayanto, Kajian Makna Panil 13, Pada Relief Lalitavistara Candi Borobudur

\section{Kepustakaan}

Hartoko, Dick, 1984, Manusia dan Seni, Kanisius, Yogyakarta

Holt, Claire, 2000, Melacak Jejak Perkembangan Seni di Indonesia, terjemahan Prof. Dr. RM. Soedarsono, Arti Line, Bandung

Magetsari, Noerhadi, 1997, Candi Borobudur, Rekonstruksi Agama dan Filsafatnya, Fakultas Sastra Universitas Indonesia, Jakarta

Maulana, Ratnaesih, 1992, Siva Dalam Berbagai Wujud, Suatu Analisis Ikonografi di Jawa Masa Hindu-Budha, UI, Jakarta

Panofsky, Erwin, 1955, Meaning in the Visual Arts, The University Chicago Press, Chicago

Rohyani, Siti, 2004, Skenario Penggambaran Relief Karmawibhanga di Candi Borobudur, UI, Jakarta

Saidi, Acep Iwan, 2008, Narasi Simbolik Seni Rupa Kontemporer Indonesia, Isacbook, Yogyakarta

Santoso, JO, 2008, Arsitektur Kota Jawa, Kosmos, Kultur dan Kuasa, Centropolis, Bandung Soekmono, 1981, Pengantar Sejarah Kebudayaan Indonesia 2, Kanisius, Yogyakarta Soetarno, 2002, Aneka Candi Kuno di Indonesia, Dahara Prize, Semarang

SP, Soedarso, 2006, Trilogi Seni, Penciptaan Eksistensi dan Kegunaan Seni, BP ISI, Yogyakarta

\section{Webtografi}

www.borobudurforumdesain.htm , 26 Desember 2010

www.kaskus.co.id/lalitavistara-page1.htm 9 September 2013 